\title{
Inadequate cancer pain management in Italian clinical trials
}

Ersilia Lucenteforte ${ }^{1, \dagger}, *$, Valentina Maggini ${ }^{1, \dagger}$, Raffaella Maione $^{2}$, Valentina Fabbroni ${ }^{3}$, Carlo Tomino ${ }^{2}$, and Alessandro Mugelli ${ }^{1,4}$

${ }^{1}$ Department of Preclinical and Clinical Pharmacology "M. Aiazzi Mancini”, Centre for Molecular Medicine (CIMMBA), University of Florence, Florence, Italy

${ }^{2}$ Research and Clinical Trial, Italian Medicines Agency, Rome, Italy

${ }^{3}$ SC Medical Oncology, Santa Maria Anunziata Hospital, Bagno a Ripoli, Florence, Italy

${ }^{4}$ Tuscan Regional Centre of Pharmacovigilance, Florence, Italy

${ }^{\dagger} \mathrm{EL}$ and VM contributed equally to this work

*Corresponding author: Ersilia Lucenteforte, $\mathrm{ScD}$

Department of Preclinical and Clinical Pharmacology

University of Florence

Viale G. Pieraccini 6 - 50139 Florence, Italy

Tel. 0554271333

Fax 0554271280

e-mail: ersilia.lucenteforte@unifi.it 


\begin{abstract}
Pain treatment in Italy is far from being optimal. In order to improve this situation, the reporting a complete assessment of pain in clinical record became compulsory by law. Pain-related cancer protocols (143) were selected from the National Monitoring Centre of Clinical Trial database and reviewed. Our data indicate that pain management was not reported as it should be: treatment has been taken into account in only $36.4 \%$ of protocols, assessment in $37.1 \%$. Furthermore, breakthrough cancer pain has never been reported. The main aim of cancer therapy is obviously control of disease, however ethical committees should pay close attention on pain therapy when evaluating clinical protocols.
\end{abstract}

Key words: guidelines; oncology; pain therapy 


\section{INTRODUCTION}

The main aim of cancer therapy is control of disease, but symptoms control and quality of life are also important for patients, families, health care providers and policy makers [1]. Furthermore, pain management is a relevant part of any end-of life treatment [2].

For patients with cancer, pain is one of the most feared symptoms [3] and it was estimated affecting $64 \%$ of patients with advanced stage or metastatic cancer disease [4].

Guideline-based treatment could significantly improve pain relief [5] and it was estimated that cancer pain may be controlled in up to $90 \%$ cases with available therapies $[6,7]$.

Despite implementation of the World Health Organization (WHO) guidelines published in 1998 [8], undertreatment of cancer pain is still present in various clinical settings [9-11] with a very high prevalence [12-16]. In Italy, a special law promulgated in 2001 entitled "Hospital without pain" sought to combat the pain in hospitals, but few hospitals, up to 2008, adopted such legislation rules [13]. In order to improve the situation, reporting a complete assessment of pain (type, measurement, treatment, relief degree) in clinical records became compulsory by law [17]. In clinical oncology protocols, many supportive treatments (antiemetic therapies, hematopoietic supportive treatment, etc.) are planned to reduce bias due to different approaches. The same should be true for pain treatment.

Our aim was to investigate if/how pain assessment (type, measurement, treatment, relief degree) is actually reported in clinical protocols approved by Italian ethical committees by conducting a review of such protocols. To the best of our knowledge, this important issue has not been addressed to date. 


\section{METHODS}

All oncology protocols approved by national ethical committees are registered in a database of the National Monitoring Centre of Clinical Trial of the Italian Medicines Agency (http://oss-sper-clin.agenziafarmaco.it/).

Pain-related cancer protocols, recorded in the above database in 2008, were selected by an expert oncologist (VF) and were used for the study. Among them, those taking into account pain treatment and measurement, were identified by searching the texts for the following themes: "pain*" combined (using the Boolean operator "and") "supportive care" or "pain management" or "pain treatment" or "analgesic*" or "morphin*" or "opioid*" or "opiate". In a second search the themes "vas" or "nrs" or "vns" or "vrs*" or "vds*" or "quality of life" were used.

Protocols including these themes were selected and independently reviewed by two investigators (EL,VM). Disagreements were resolved by discussion and consensus. To validate the search strategy, $10 \%$ of excluded protocols were randomly selected for further review.

\section{RESULTS}

In 2008, the National Monitoring Centre of Clinical Trial database recorded 242 oncology studies. Figure 1 gives the flowchart for the selection of protocols. Nine protocols were excluded because they were not complete, 5 because they focused on pain. Among the remaining 228 protocols, 143 were selected by the oncologist.

Eighty-fifty of $143(59.4 \%)$ were studies promoted and sponsored by drug companies, the remaining were no-profit ones (oncology cooperative groups, scientific 
societies, etc.). Seventy-nine studies (55.2\%) were phase II clinical trials, 47 studies (32.9\%) were phase III clinical trials, the remaining were phase I one. As concern cancer site, 29 studies (20.3\%) were on lung cancer, 20 (14.0\%) on breast cancer, and $16(11.2 \%)$ on colorectal cancer.

Table 1 gives the distribution of 143 protocols included in the present study according to the presence of pain therapy or supportive care and pain assessment. Pain treatment has been taken into account in 52 protocols (36.4\%), analgesics generic use in 35 protocols $(67.3 \%)$, opiates use in 11 protocols $(21.2 \%)$ - only 2 of these 11 protocols reported specific guidelines -, and pain treatment without mentioning any drugs in 6 protocols $(11.5 \%)$. Moreover, supportive care without mentioning pain has been reported in 26 protocols (18.2\%), and breakthrough cancer pain has never been reported. As concern pain assessment, it was considered in 53 protocols (37.1\%): 9 protocols (17.0\%) adopted a specific questionnaire (i.e., Brief Pain Inventory Questionnaire, McGill Pain Questionnaire, and Present Pain Intensity Questionnaire), and 44 protocols (83.0\%) adopted a questionnaire about quality of life including at least a specific item on pain (i.e., European Organization for Research and treatment of Cancer - EORTC - Quality of Life Questionnaires - QLQ -, Functional Assessment of Cancer Therapy - FACT- Questionnaires, and EuroQol 5 Dimensional - EQ5D Questionnaire). Twenty-five protocols (17.5\%) included both pain treatment and assessment.

\section{DISCUSSION}

Our data indicate that in 2008 pain treatment and assessment are not still reported in oncology clinical protocols as it should be. Pain treatment has been taken into account 
in only $36.4 \%$ of protocols, pain assessment in $37.1 \%$. Furthermore, breakthrough cancer pain has never been reported.

A review on studies, conducted between 1987 and 2007, aimed to assess adequacy of pain control showed that nearly one of two patients (43\%) was undertreated [12]. The prevalence of undertreatment ranged from as high as $82 \%$ in a clinical trial from Italy [18] to 7-9\% in a survey from the United Kingdom [19]. Studies conducted after the above review showed similar results. The European Pain in Cancer survey sought to increase understanding of cancer-related pain and treatment across Europe and highlighted for the first time that cancer pain remained an issue and it was far from being optimal [14]. As regard Italy, the same survey showed inadequate treatment in $47 \%$ of cases. The same situation could likely be applied to non-cancer pain even if it is certainly misleading to assume that cancer pain is better managed than other types of chronic non-malignant pain. In this line, it could be interesting to evaluate protocols of clinical studies on pain-related non-cancer disease.

An Italian multicenter study focused on the evaluation of the epidemiology, patterns and quality of pain care of cancer patients, showed a high (around 50\% in some subgroups) prevalence of analgesic undertreatment [15]. Finally, an Italian crosssectional survey showed that a significant proportion of patients with moderate-severe pain did not receive appropriate medication and $20 \%$ received no treatment [16].

The reason why cancer pain is undertreated in Italy is not obvious. One reason could be because guidelines, which are available and in some case also published by Italian scientific societies [20-22] are not followed by physicians. More likely, suboptimal pain control could be due to the non-homogeneous service development for patients with pain, to cultural barriers and poor guidelines dissemination [15]. 
In any case, substantial obstacles to adequate pain relief with opioids include specific concerns of patients themselves, their family members, physicians, nurses, and the healthcare system [23].

In conclusion, the results of the present analysis on all studies recorded in 2008 could be interpreted as the real situation of Italian oncology research. We suggest that ethical committees should pay close attention on pain therapy when evaluating oncology clinical study protocols, according to the law approved in 2010 [17]. The present analysis will be replicated when data on a significant number of oncology studies started after 2010 will be available. 


\section{REFERENCES}

1. Potter J, Higginson IJ (2004) Pain experienced by lung cancer patients: a review of prevalence, causes and pathophysiology. Lung Cancer 43 (3):247-257.

2. Lacey J, Sanderson C (2010) The oncologist's role in care of the dying cancer patient. Cancer J 16 (5):532-541.

3. Portenoy RK, Lesage P (1999) Management of cancer pain. Lancet 353 (9165):16951700 .

4. van den Beuken-van Everdingen MH, de Rijke JM, Kessels AG, Schouten HC, van Kleef M, Patijn J (2007) Prevalence of pain in patients with cancer: a systematic review of the past 40 years. Ann Oncol 18 (9):1437-1449.

5. Dy SM, Asch SM, Naeim A, Sanati H, Walling A, Lorenz KA (2008) Evidence-based standards for cancer pain management. J Clin Oncol 26 (23):3879-3885.

6. Mercadante S (1999) Pain treatment and outcomes for patients with advanced cancer who receive follow-up care at home. Cancer 85 (8):1849-1858.

7. Grond S, Zech D, Diefenbach C, Radbruch L, Lehmann KA (1996) Assessment of cancer pain: a prospective evaluation in 2266 cancer patients referred to a pain service. Pain 64 (1):107-114.

8. World Health Organization (WHO) (1998) Cancer pain relief and palliative care in children. WHO, Geneva, England

9. Cleeland CS, Gonin R, Hatfield AK, Edmonson JH, Blum RH, Stewart JA, Pandya KJ (1994) Pain and its treatment in outpatients with metastatic cancer. N Engl J Med 330 (9):592596.

10. Urban D, Cherny N, Catane R (2010) The management of cancer pain in the elderly. Crit Rev Oncol Hematol 73 (2):176-183.

11. Kart T, Christrup LL, Rasmussen M (1997) Recommended use of morphine in neonates, infants and children based on a literature review: Part 2--Clinical use. Paediatr Anaesth 7 (2):93-101.

12. Deandrea S, Montanari M, Moja L, Apolone G (2008) Prevalence of undertreatment in cancer pain. A review of published literature. Ann Oncol 19 (12):1985-1991.

13. Varrassi G, Raffaeli W, Marinangeli F, Ursini ML, Piroli A, Paladini A, Righetti D, Monterubbianesi MC, Andruccioli J, Sarti D (2008) Epidemiology and treatment of pain in Italy: part I. European Journal of Pain Supplements 2:44-46.

14. Breivik H, Cherny N, Collett B, de Conno F, Filbet M, Foubert AJ, Cohen R, Dow L (2009) Cancer-related pain: a pan-European survey of prevalence, treatment, and patient attitudes. Ann Oncol 20 (8):1420-1433.

15. Apolone G, Corli O, Caraceni A, Negri E, Deandrea S, Montanari M, Greco MT (2009) Pattern and quality of care of cancer pain management. Results from the Cancer Pain Outcome Research Study Group. Br J Cancer 100 (10):1566-1574.

16. Mercadante S, Roila F, Berretto O, Labianca R, Casilini S (2008) Prevalence and treatment of cancer pain in Italian oncological wards centres: a cross-sectional survey. Support Care Cancer 16 (11):1203-1211.

17. Gazzetta Ufficiale n. 65,19 March 2010. Law no. 38, Art. 51, 13 March 2010.

18. Di Maio M, Gridelli C, Gallo C, Manzione L, Brancaccio L, Barbera S, Robbiati SF, Ianniello GP, Ferrau F, Piazza E, Frontini L, Rosetti F, Carrozza F, Bearz A, Spatafora M, Adamo V, Isa L, Iaffaioli RV, Di Salvo E, Perrone F (2004) Prevalence and management of pain in Italian patients with advanced non-small-cell lung cancer. Br J Cancer 90 (12):22882296.

19. Russell PB, Aveyard SC, Oxenham DR (2006) An assessment of methods used to evaluate the adequacy of cancer pain management. J Pain Symptom Manage 32 (6):581-588. 
20. Pigni A, Brunelli C, Gibbins J, Hanks G, Deconno F, Kaasa S, Klepstad P, Radbruch L, Caraceni A (2010) Content development for EUROPEAN GUIDELINES on the use of opioids for cancer pain: a systematic review and Expert Consensus Study. Minerva Anestesiol 76 (10):833-843.

21. Swarm R, Abernethy AP, Anghelescu DL, Benedetti C, Blinderman CD, Boston B, Cleeland C, Coyle N, Deleon-Casasola OA, Eilers JG, Ferrell B, Janjan NA, Karver SB, Levy MH, Lynch M, Moryl N, Murphy BA, Nesbit SA, Oakes L, Obbens EA, Paice JA, Rabow MW, Syrjala KL, Urba S, Weinstein SM (2010) Adult cancer pain. J Natl Compr Canc Netw 8 (9):1046-1086.

22. Cachia E, Ahmedzai SH (2011) Transdermal opioids for cancer pain. Curr Opin Support Palliat Care 5 (1):15-19.

23. Christo PJ, Mazloomdoost D (2008) Cancer pain and analgesia. Ann N Y Acad Sci 1138:278-298. 


\section{FIGURE LEGENDS}

Figure 1 - flowchart of protocol selection. 
Table 1 - Distribution of 143 oncology clinical trial protocols recorded in 2008 by the National Monitoring Centre of Clinical Trial of the Italian Medicines Agency included in the present study according to the presence of pain therapy or supportive care and pain measure.

$\mathrm{N}(\%)$

Therapy

Pain therapy

Analgesics generic use

Opiates use

Pain treatment without mentioning any drugs

$6(11.5)$

Supportive care not specifying pain

Not specified

Absence of pain therapy or supportive care

$60(41.9)$

Pain measure

Yes

Questionnaire focused on pain

Questionnaire about quality of life

Unclear

No

$86(60.1)$

\footnotetext{
${ }^{\mathrm{a}}$ Two out of 11 comprised pain treatment guidelines.

${ }^{\mathrm{b}}$ Brief Pain Inventory Questionnaire, McGill Pain Questionnaire, and Present Pain Intensity Questionnaire.

${ }^{c}$ European Organization for Research and treatment of Cancer (EORTC), Quality of Life Questionnaires (QLQ), Functional Assessment of Cancer Therapy (FACT) Questionnaires, and EuroQol 5 Dimensional (EQ5D) Questionnaire.
} 


\section{Figure 1}

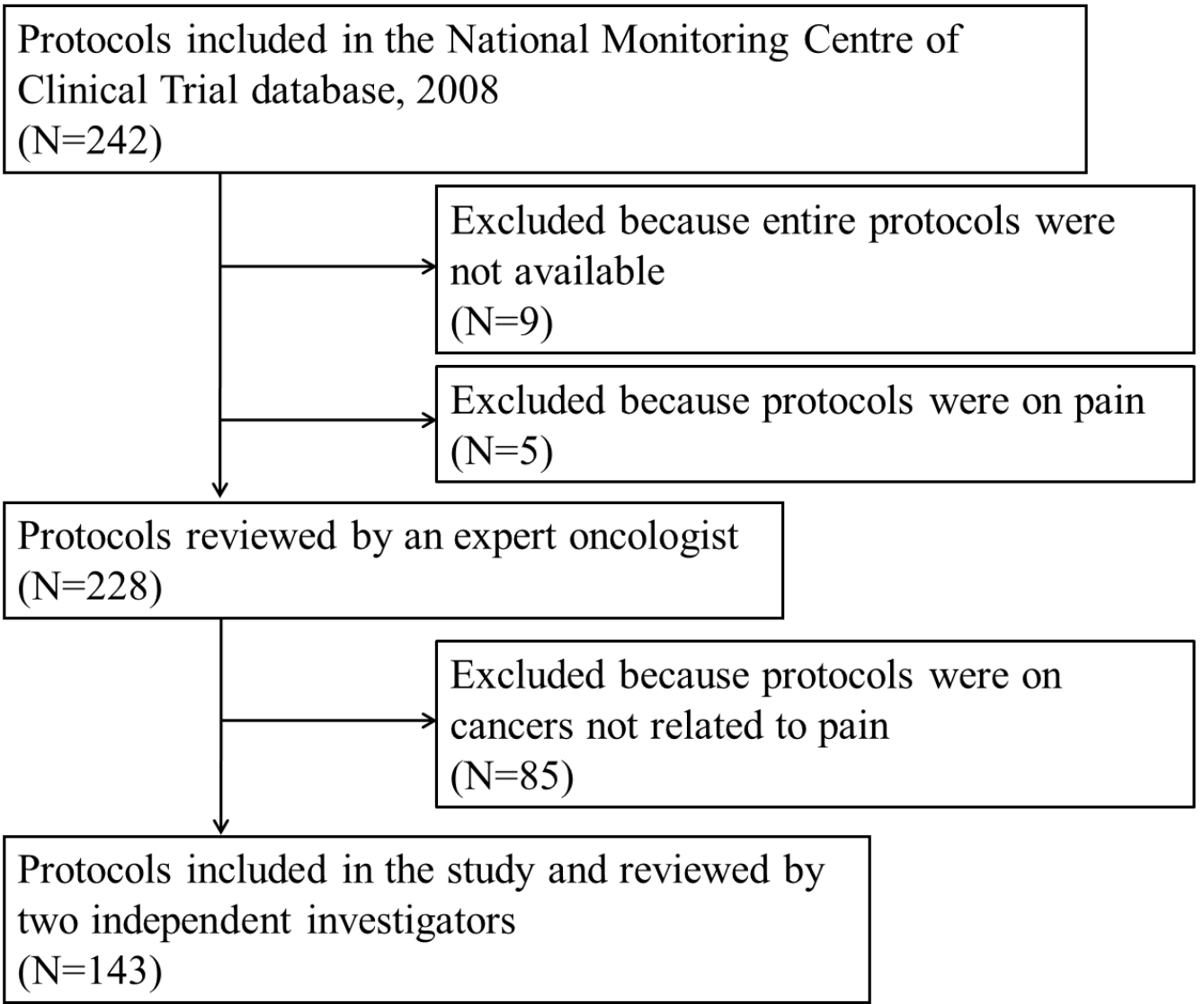

